\title{
Prediction of postoperative nausea vomiting, using Japanese traditional Kampo medicine, "Water Stagnation Score"
}

\author{
Yusuke Kasuya M.D., Ikue Furui M.D., Risa Fukushima M.D., \\ Keiko Kume* M.D., Makoto Ozaki M.D. \\ Department of Anesthesiology, Tokyo Women's Medical University \\ Department of Anesthesiology, Osaka University*
}

Background and Goal of Study:

Japanese traditional Kampo medicine has a unique methodology of human body constitution classification. Kampo medicine specific concept, "Water stagnation" is considered as a status of abnormal fluid distribution state with the body feature tendency of accumulating unnecessary body fluid and blunting fluid elimination function, and has been reported to be a high risk for nausea and vomiting. The purpose of this study is to clarify whether water stagnation score (WSS), which is calculated using a self-assessed questionnaire, is useful to predict PONV for the gynecological patients.

\begin{tabular}{|l|c|}
\hline \multicolumn{1}{c|}{ Water Stagnation Score } & Score \\
\hline Questionnaire & 3 \\
\hline Heaviness of the body & 4 \\
\hline Throbbing headache & 3 \\
\hline Heaviness of the head & 5 \\
\hline Motion sickness & 5 \\
\hline Dizziness & 5 \\
\hline Lightheadedness upon standing & 3 \\
\hline Watery nasal discharge & 3 \\
\hline Excessive salivary & 4 \\
\hline Foamy sputum & 3 \\
\hline Nausea/vomiting & 3 \\
\hline Hyperdynamic bowel sound & 7 \\
\hline Morning stiffness & 15 \\
\hline Splashing sound in epigastric region, edematous & 15 \\
\hline Pleural effusion, cardiac effusion, ascites & 5 \\
\hline Brisk pulsation in the supra-umbilical region & 5 \\
\hline Watery diarrhea & 7 \\
\hline Oliguria & 5 \\
\hline Polyuria & \\
\hline The sum score was calculated as the Water stagnation score. If \\
the extent of each symptom is slight, half of the score is given. \\
WSS $\geqq 13$ is considered as the positive water stagnation state.
\end{tabular}

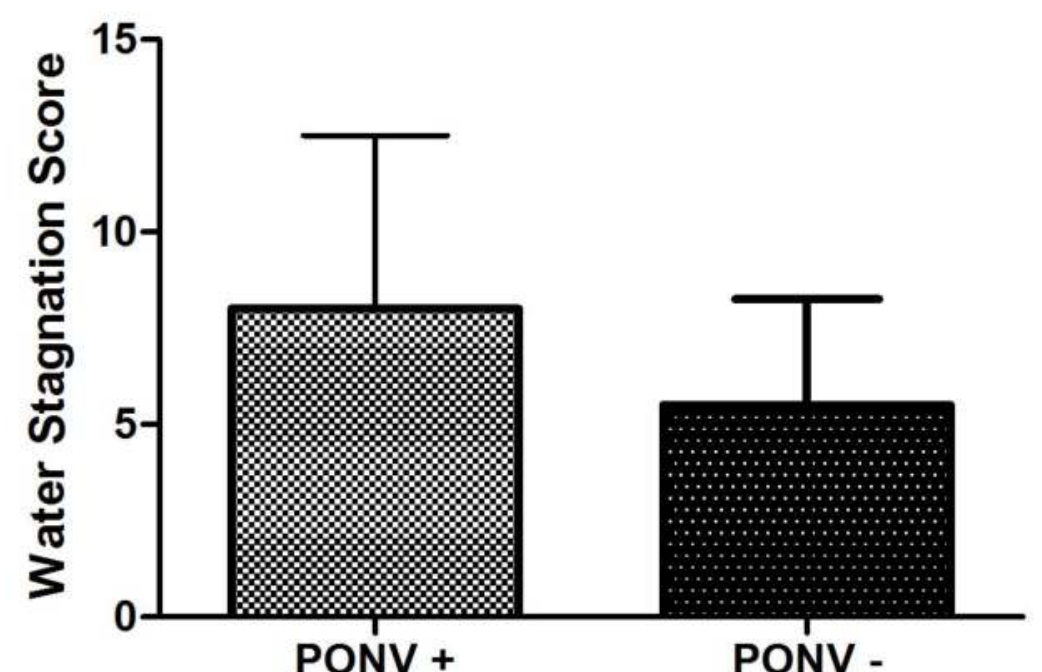

Figure. 1

WSS was $7.3 \pm 7.8$ in control group (PONV -), and $10.4 \pm 7.0$ in PONV group $(p=0.073)$.

PONV + PONV

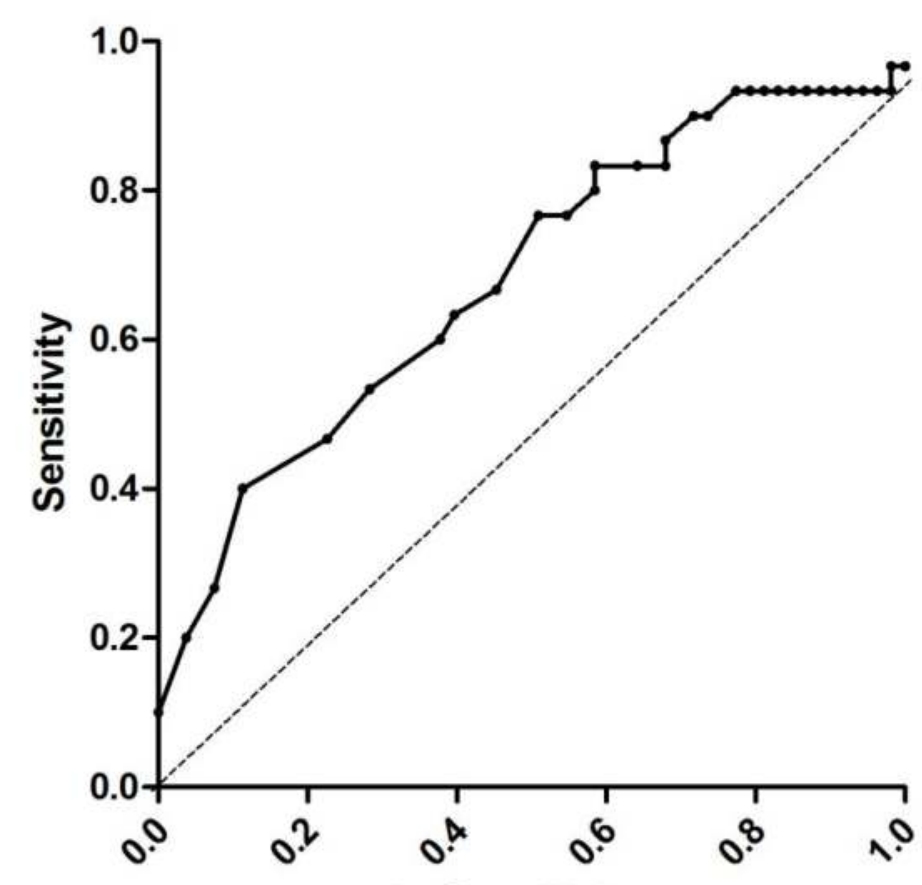

Figure. 2

ROC analysis; PONV within 6 hours postoperatively. Sensitivity was 0.86 and specificity was 0.32 , and area under curve was 0.68 with cut off WSS value of 13

\section{Materials and Methods:}

WSS was preoperatively assessed. Inclusion criteria were 1) elective gynecological surgery, 2) aged 20 to 50 years, and 3) scheduled expected procedure time $>2$ hours. Exclusion criteria were 1)ASA-PS 3 or more, 2) body mass index 35 or more, 3) pregnant and lactating women, 4) regular use of any Kampo medicine, and 5) use of steroids, immunosuppressive or chemotherapy medicines. PONV incidence during first 6 hours after general anesthesia was assessed, and patients were divided into PONV group or control group (no PONV). WSS was compared between groups. The unpaired t-test or Mann-Whitney U-test was applied.

\section{Results and Discussion:}

Eighty three patients were studied, and 53 patients developed PONV in the first 6 hour postoperatively. WSS was $7.3 \pm 7.8$ in control group, and 10.4 \pm 7.0 in PONV group $(p=0.073)$. Incidence of water stagnation state (WSS $\geq 13$ ), was $3.4 \%$ in control group and $20.1 \%$ in PONV group ( $\mathrm{p}=0.01$ ). In ROC analysis, sensitivity was 0.86 and specificity was 0.32 , and area under curve was 0.68 with cut off WSS value of 13 .

\begin{tabular}{|l|l|l|l|}
\hline & PONV - & PONV + & \\
\hline Age (years) & $\mathrm{n}=30$ & $\mathrm{n}=53$ & $\mathrm{p}$-value \\
\hline Height (cm) & $37.5 \pm 7.8$ & $38.8 \pm 8.0$ & 0.47 \\
\hline Body weight $(\mathrm{kg})$ & $158 \pm 7.7$ & $159 \pm 4.4$ & 0.51 \\
\hline BMl (kg/cm $\left.{ }^{2}\right)$ & $60.3 \pm 13.8$ & $55.4 \pm 9.5$ & 0.048 \\
\hline & $24.6 \pm 5.7$ & $22.0 \pm 3.7$ & 0.025 \\
\hline $\begin{array}{l}\text { Preop systolic Blood } \\
\text { pressure (mmHg) }\end{array}$ & $122 \pm 17$ & $110 \pm 15$ & 0.008 \\
\hline Preop body temperature & $36.7 \pm 0.3$ & $36.6 \pm 0.4$ & 0.4 \\
\hline & & & \\
\hline Water stagnation score & $7.3 \pm 7.8$ & $10.4 \pm 7.0$ & 0.073 \\
\hline WSS $>13$ & $1(3.4 \%)$ & $11(20.1 \%)$ & 0.01 \\
\hline Apfel score & $3[4,3]$ & $3[3,3]$ & 0.15 \\
\hline \multicolumn{1}{|l|}{ Motion sickness } & $30 \%$ & $54.7 \%$ & 0.03 \\
\hline Previous PONV & $0 \%$ & $9.40 \%$ & 0.08 \\
\hline Dizziness & $10 \%$ & $34 \%$ & 0.015 \\
\hline Smoking history & $23 \%$ & $26 \%$ & 0.75 \\
\hline & & & \\
\hline Laparoscopic & $46.7 \%$ & $45.3 \%$ & 0.89 \\
\hline Procedure Time & $118 \pm 42$ & $139 \pm 53$ & 0.07 \\
\hline Blood loss (g) & $138 \pm 267$ & $229 \pm 367$ & 0.27 \\
\hline Remifentanil Dose (mg) & $3.9 \pm 1.1$ & $4.2 \pm 1.4$ & 0.33 \\
\hline Fentanyl Dose (mcg) & $545 \pm 94$ & $520 \pm 97$ & 0.29 \\
\hline Sevoflurane (mL) & $37.7 \pm 17.0$ & $35.6 \pm 17.5$ & 0.6 \\
\hline
\end{tabular}

\section{Conclusion:}

As WSS can classify the human physical constitution more precisely than Apfel score, WSS is a useful predictor of PONV for gynecological surgical patients. 